\title{
Quantitative assessment of microalgae biomass and lipid stability post-cultivation
}

\section{Katerine Napan, Tyler Christianson, Kristen Voie and Jason C. Quinn*}

Department of Mechanical and Aerospace Engineering, Utah State University, Logan, UT, USA

Edited by:

Umakanta Jena, Desert Research Institute, USA

\section{Reviewed by:}

S. Kent Hoekman, Desert Research Institute, USA

Ben J. Stuart, Ohio University, USA

*Correspondence:

Jason C. Quinn, Department of

Mechanical and Aerospace

Engineering, Utah State University,

4130 Old Main Hill, Logan, UT

84322-4130, USA

e-mail: jason.quinn@usu.edu
Processing of microalgal biomass to biofuels and other products requires the removal of the culture from a well-controlled growth system to a containment or preprocessing step at non-ideal growth conditions, such as darkness, minimal gas exchange, and fluctuating temperatures. The conditions and the length of time between harvest and processing will impact microalgal metabolism, resulting in biomass and lipid degradation. This study experimentally investigates the impact of time and temperature on Nannochloropsis salina harvested from outdoor plate photobioreactors. The impact of three temperatures, 4, 40, or $70^{\circ} \mathrm{C}$, on biomass and lipid content (as fatty acid methyl esters) of the harvested microalgae was evaluated over a $156 \mathrm{~h}$ time period. Results show that for $N$. salina, time and temperature are key factors that negatively impact biomass and lipid yields. The temperature of $70^{\circ} \mathrm{C}$ resulted in the highest degradation with the overall biofuel potential reduced by $30 \%$ over $156 \mathrm{~h}$. Short time periods, $24 \mathrm{~h}$, and low temperatures are shown to have little effect on the harvested biomass.

Keywords: microalgae, biomass, lipid, FAME, losses, harvest, Nannochloropsis salina, microalgal storage

\section{INTRODUCTION}

Microalgae cultivation has been intensely studied in the past decades due to inherent advantages such as high biomass and lipid productivities, capacity to be grown in non-arable land, utilization of low quality and saline water, and integration with point source waste streams (Khan et al., 2009; Mata et al., 2010). Technological hurdles in the growth, dewater, and conversion steps of the feedstock to biofuel process has limited the scale at which production has been demonstrated (Quinn et al., 2012). Cultivation systems, which include photobioreactors (PBR) and open raceway ponds, have been used at pilot plant scale to produce biomass, which is typically harvested, preserved, and processed off site. Large-scale systems will integrate on site processing based on environmental and economic benefits (Batan et al., 2010; Lundquist et al., 2010; Davis et al., 2011, 2014; Beal et al., 2012; Quinn et al., 2014; Rogers et al., 2014; Thilakaratne et al., 2014; Woertz et al., 2014). Current uncertainties in the structure of a large-scale algal based biorefineries make it possible that microalgae biomass will be temporarily stored in holding tanks based on dewatering processing capacity. Further, the possibility exists for long-term storage due to equipment malfunction or limitations in downstream processing. The tolerance of algal biomass to time and temperature must be understood such that yield is not impacted from biomass and lipid degradation prior to recovery.

During microalgae production, cells are exposed to conditions that ensure biomass multiplication and lipid accumulation. Environmental conditions such as nutrient load, carbon dioxide, light, and temperature are well constrained by the cultivation system and optimized for microalgae growth and stability. However, during harvesting and preprocessing, these conditions are abruptly terminated and new conditions, previously avoided in a controlled growth system develop. Depending on the harvesting method and processing capacity, the conditions and time of exposure vary. Generally, during the collection and transport of microalgae from the cultivation system to a centralized separation facility, the cells are not exposed to sunlight and the culture temperature is a function of meteorological conditions. During this time period, microalgae are still carrying out physiological activities under non-ideal conditions. As a result, the cells and their contents will undergo physiological changes that could negatively affect the biomass and bio-products yields.

Several factors are known to contribute to biomass and lipid losses. These losses are known to be accelerated by rising temperatures. Low temperatures can reduce the reaction rate of enzyme-catalyzed metabolic reactions in microalgal cells (Mishra and Gamage, 2007). The length of harvest is also known to influence biomass, as organisms need energy to continue cell functions (Montaini et al., 1995). Microalgae-related literature addressing these factors is limited with few studies presenting data related to biomass and lipid degradation. Previous work has focused on carbon isotope fractionation, microalgae respiration rate, and microalgae decomposition in natural environments. The application of results to microalgae biorefinery systems is limited. Additionally, several techno-economic and life cycle assessments of the microalgae biofuel process do not consider the impact of storage time or preprocessing temperatures on yield as all assume a seamlessly integrated co-located growth and processing facility (Batan et al., 2010; Beal et al., 2012; Sills et al., 2012; Jones et al., 2014; Quinn et al., 2014; Rogers et al., 2014; Thilakaratne et al., 2014; Woertz et al., 2014). Current assessments of the microalgae to biofuels process make simplifying assumption due to the lack of large-scale processing data (Davis et al., 
2014). Currently, there is a need to develop data that can be leveraged to validate engineering system process models for improved fidelity in large-scale feasibility assessments of microalgae biofuel systems.

This study experimentally evaluates the impact of time and temperature on microalgae biomass and lipid composition as applied for use as a biodiesel feedstock. The experimental system was designed to be representative of a large-scale microalgae processing system through the harvesting phase. In large-scale systems, it is expected, based on variable production and fixed processing capacity, there will be storage of culture for a nontrivial time period. This study presents results in terms of changes in Nannochloropsis salina biomass and lipid quantity (produced in outdoor flat-plate PBR) stored under three different temperatures, $4^{\circ} \mathrm{C}$ (refrigeration), $40^{\circ} \mathrm{C}$ (outdoor storage in summer), and $70^{\circ} \mathrm{C}$ (pasteurization or upper storage bound), over the course of $156 \mathrm{~h}$. Discussion includes the impact of the results on the microalgae industry and on scalability assessments.

\section{MATERIALS AND METHODS}

Nannochloropsis salina was cultivated in outdoor PBR with the collected biomass analyzed as a function of time and temperature. Harvested biomass was collected in $50 \mathrm{~mL}$ aliquots and exposed to three different temperatures. Periodic collection of samples were centrifuged and analyzed for biomass and lipid content. Experiments were performed in triplicate with the baseline biomass and lipid content being time 0 .

\section{ORGANISM PRODUCTION}

Nannochloropsis salina was grown in flat-plate PBR $(110 \mathrm{~cm} \times$ $241 \mathrm{~cm} \times 5 \mathrm{~cm}$ ) with a maximum capacity of $130 \mathrm{~L}$ of culture. The PBRs were located in a greenhouse with supplemental high pressure sodium lighting (Utah State University Research Greenhouse). Temperature was maintained at $23^{\circ} \mathrm{C}$ in the PBR through a chilled water heat exchanger. Mixing of the system was maintained through sparge air supplied through a stainless steel manifold in the bottom of the PBR. The $\mathrm{pH}$ was maintained at 7.3 through automatic injection of carbon dioxide into the sparge air based on $\mathrm{pH}$ feedback. Prior to inoculation, PBRs were washed and bleached overnight, followed by rinsing with tap water.

Nutrient medium was prepared using tap water, sodium chloride $\left(\mathrm{NaCl}, 17.5 \mathrm{~g} \mathrm{~L}^{-1}\right)$, calcium chloride dihydrate $\left(\mathrm{CaCl}_{2} \times\right.$ $\left.2 \mathrm{H}_{2} \mathrm{O}, 1.5 \times 10^{-1} \mathrm{~g} \mathrm{~L}^{-1}\right)$, potassium chloride $\left(\mathrm{KCl}, 4.8 \times 10^{-1}\right.$ $\left.\mathrm{gL}^{-1}\right)$, sodium metasilicate non-ahydrate $\left(\mathrm{Na}_{2} \mathrm{SiO}_{3} \times 9 \mathrm{H}_{2} \mathrm{O}\right.$, $\left.5.7 \times 10^{-2} \mathrm{~g} \mathrm{~L}^{-1}\right)$, magnesium sulfate heptahydrate $\left(\mathrm{MgSO}_{4} \times\right.$ $\left.7 \mathrm{H}_{2} \mathrm{O}, 1.48 \mathrm{~g} \mathrm{~L}^{-1}\right)$, potassium nitrate $\left(\mathrm{KNO}_{3}, 1.02 \mathrm{~g} \mathrm{~L}^{-1}\right)$, potassium phosphate monobasic $\left(\mathrm{KH}_{2} \mathrm{PO}_{4}, 6.8 \times 10^{-2} \mathrm{gL}^{-1}\right)$, ammonium ferric citrate $\left(5.2 \times 10^{-3} \mathrm{~g} \mathrm{~L}^{-1}\right)$, boric acid $\left(\mathrm{H}_{3} \mathrm{BO}_{3}\right.$, $\left.9.0 \times 10^{-4} \mathrm{~g} \mathrm{~L}^{-1}\right)$, disodium molybdenate dihydrate $\left(\mathrm{Na}_{2} \mathrm{MoO}_{4} \times\right.$ $\left.2 \mathrm{H}_{2} \mathrm{O}, 1.2 \times 10^{-5} \mathrm{~g} \mathrm{~L}^{-1}\right)$, manganese chloride tetrahydrate $\left(\mathrm{MnCl}_{2} \times 4 \mathrm{H}_{2} \mathrm{O}, 3.0 \times 10^{-4} \mathrm{~g} \mathrm{~L}^{-1}\right)$, zinc sulfate heptahydrate $\left(\mathrm{ZnSO}_{4} \times 7 \mathrm{H}_{2} \mathrm{O}, 6.0 \times 10^{-5} \mathrm{~g} \mathrm{~L}^{-1}\right)$, cupric sulfate pentahydrate $\left(\mathrm{CuSO}_{4} \times 5 \mathrm{H}_{2} \mathrm{O}, 2.0 \times 10^{-5} \mathrm{~g} \mathrm{~L}^{-1}\right), 0.1 \mathrm{mM}$ biotin $(40.9 \mu \mathrm{L})$, $6.5 \mathrm{mM}$ thiamine $(26.08 \mu \mathrm{L})$, and $0.135 \mathrm{mg} \mathrm{mL}^{-1}$ vitamin $\mathrm{B}_{12}$ $(14.81 \mu \mathrm{L})$. Microalgae were harvested from the PBRs when the culture concentration reached at least $2 \mathrm{~g} \mathrm{~L}^{-1}$.

\section{DEGRADATION EXPERIMENTAL SET-UP}

This study is a time series experiment with time as an independent variable and temperature as controlled variable. The dependent variable or measured responses were either biomass or lipid content. The measured response at different times is compared against the initial conditions before the temperature treatment (in this case, the biomass and lipid content at time 0 ). The duration of the experiment was at the least $156 \mathrm{~h}$ with sampling events within 12 and $24 \mathrm{~h}$ from each other (one sample event was lost during the lipid analysis).

For the determination of biomass degradation, microalgae cultivated in flat-plate PBR located at the USU Research Greenhouse facility were harvested and were immediately transferred into seventy two $50 \mathrm{~mL}$ polypropylene centrifuge tubes. The vials were separated into three groups of 24 vials. From each group of 24 vials, 3 vials, to be used as samples at time 0 , were immediately centrifuged (RC-6 Plus, Thermo Fisher, USA), the supernatant was discarded and the pellet was preserved in a $-80^{\circ} \mathrm{C}$ freezer. The biomass content in these vials was used as the initial untreated response. The remaining 21 vials left in each batch were placed in one of three water baths maintained at $4^{\circ} \mathrm{C}$ (represent refrigeration), $40^{\circ} \mathrm{C}$ (represent outdoor storage in summer), or $70^{\circ} \mathrm{C}$ (represent pasteurization or upper storage bound). The water baths were maintained in complete darkness with minimal light exposure during sampling. During sampling, three vials were collected from each water bath. The vials were immediately centrifuged, and the pellets were preserved at $-80^{\circ} \mathrm{C}$. Frozen biomass pellets were put in a lyophilizer (FreeZone 6, Labconco, USA) overnight at $-50^{\circ} \mathrm{C}$ under $0.1 \mathrm{mBar}$ vacuum for complete dewatering. Freeze dried samples were used to determine biomass loss. Biomass was measured through analyzing the mass remaining in harvested samples after centrifugation. At the end of the experiment, the freeze dried microalgae were powdered using a mortar and pestle and was preserved at $-80^{\circ} \mathrm{C}$ until fatty acid methyl ester (FAME) analysis.

\section{LIPID ANALYSIS}

Total lipids were quantified through FAME content with results expressed as percent FAME content based on microalgal biomass dry weight ( $\%$ of total DW). This approach to measure lipids accurately reflects the biofuel potential (Wychen and Laurens, 2013). FAMEs were produced through an acid-catalyzed in situ transesterification technique. Approximately, $100 \mathrm{mg}$ was transferred into test tubes (borosilicate tubes with screw cap, Fisher Scientific, USA). A $2 \mathrm{~mL}$ solution of a $2 \%$ sulfuric acid in methanol (v/v) was added to the vials that were then sealed. Vials were digested at $80^{\circ} \mathrm{C}$ for $90 \mathrm{~min}$ in a digital reactor block (DBR200, $\mathrm{HACH}$, USA) shaking the tube contents vigorously every $15 \mathrm{~min}$. Digested contents were transferred to a borosilicate test tube. Digestion vials were then rinsed three times with $1 \mathrm{~mL}$ chloroform and the rinsing solution transferred to the test tubes.

The methanol, sulfuric acid, chloroform, and biomass mixture were then washed with an equal volume of deionized water delivered using a washing/dispensing bottle (with nozzle) that allowed for a well stirred solution. Vials were then centrifuged for phase separation. The upper methanol and water phase was discarded and the water washing step was repeated two times more. The bottom phase containing the chloroform and FAME was transferred 
to a $10 \mathrm{~mL}$ volumetric flask using a $5 \mathrm{~mL}$ glass gas-tight syringe. The syringe and the test tube were rinsed two times more using chloroform with the rinse transferred into the $10 \mathrm{~mL}$ volumetric flask. The final volume in the volumetric flask was adjusted to $10 \mathrm{~mL}$ using chloroform, and the contents were mixed thoroughly. From this solution, $1 \mathrm{~mL}$ was transferred to an amber borosilicate screw top vial for analysis by gas chromatograph (Model 7890A GC System, Agilent Technologies, USA) equipped with a flame ionization detector (FID) and autosampler. The column used was a capillary column with polyethylene glycol stationary phase Stabilwax-DA (RESTEK), length $30 \mathrm{~m}$, internal diameter $0.32 \mathrm{mM}$, and film thickness $0.25 \mu \mathrm{m}$. The inlet temperature used was of $250^{\circ} \mathrm{C}$, oven temperature used was of $100^{\circ} \mathrm{C}$ for $1 \mathrm{~min}$, $25^{\circ} \mathrm{C} / \mathrm{min}$ up to $200^{\circ} \mathrm{C}$, and held for $1 \mathrm{~min}, 5^{\circ} \mathrm{C} / \mathrm{min}$ up to $250^{\circ} \mathrm{C}$ and held for $7 \mathrm{~min}$. The FID was held at $280^{\circ} \mathrm{C}$. Standards using methyl myristate, methyl palmitoleate, and methyl oleate were prepared in a chloroform matrix and run in parallel with the prepared samples.

\section{RESULTS}

Time and temperature were shown to be critical factors for $N$. salina biomass yields. Figure 1 shows the decrease of biomass with time at the three temperatures tested. For experiments at $4^{\circ} \mathrm{C}$ biomass losses were minimal, with biomass content becoming statistically different to the initial biomass after $132 \mathrm{~h}$ (ANOVA, $p<0.05)$. In contrast, for experiments at 40 and $70^{\circ} \mathrm{C}$ the biomass contents were statistically different to the initial biomass (ANOVA, $p<0.05)$ starting at the first sampling of the experiment, $12 \mathrm{~h}$. The slope of the decrease in biomass content was more pronounced at the beginning of the experiment (during the first $60 \mathrm{~h}$ ) and became mild after this period.

The time evolution of percent FAME content ( $\%$ of total DW) at 4,40 , and $70^{\circ} \mathrm{C}$ is shown in Figure 2. Figure 2A shows an initial increase in percent FAME ( $\%$ of total DW). Similar behavior was observed by Montaini et al. (1995). A second experiment was performed to further investigate initial lipid increase. Results from this study are presented in Figure 3 and show a slight increase in percent FAME initially for the $40^{\circ} \mathrm{C}$ experiment with minimal

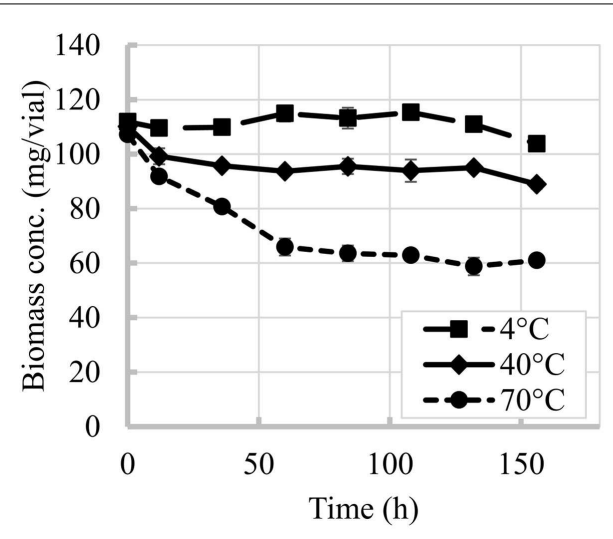

FIGURE 1 |Time evolution of $\boldsymbol{N}$. salina biomass content at different temperatures. Error bars represent SD from three independent experiments. SD not visible is overlapped with the symbols. degradation in the latter part of the experiment. The $70^{\circ} \mathrm{C}$ experiment was not statistically different from the initial percent FAME content ( $\%$ of total DW) while the $4^{\circ} \mathrm{C}$ experiment was slightly
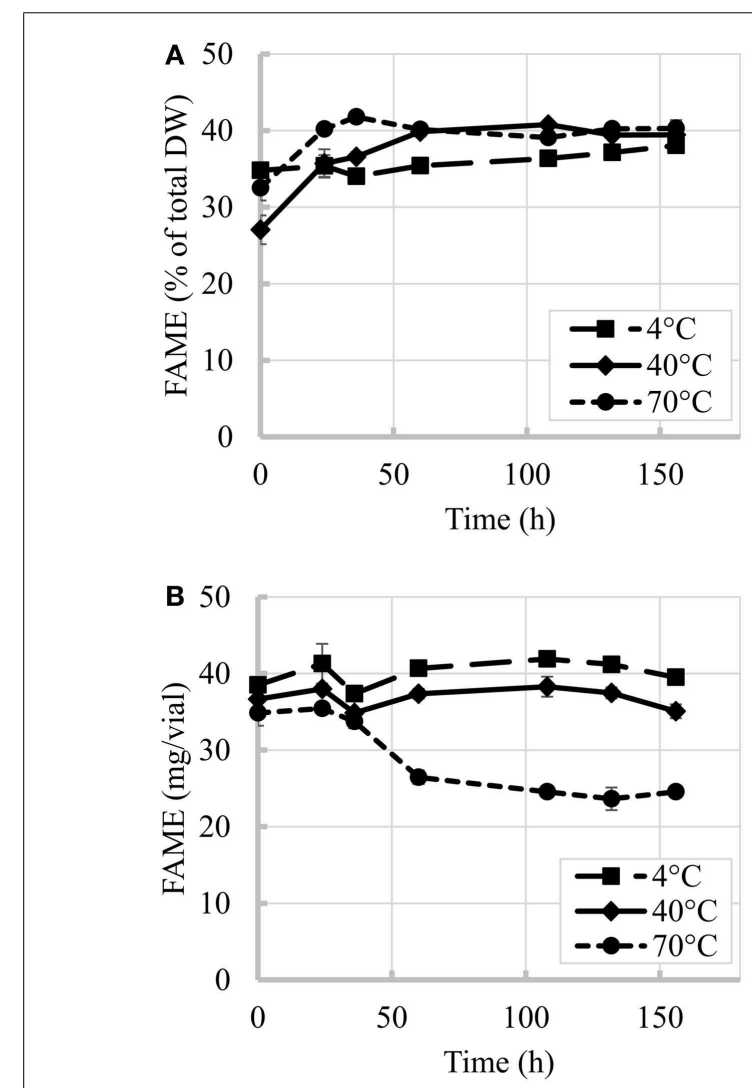

FIGURE 2 |Time evolution of FAME content at three different temperatures. (A) Percent FAME per unit of biomass (\% total DW), (B) Total FAME per vial. Initial biomass was $2 \mathrm{~g} / \mathrm{L}$. Error bars represent SD from three independent experiments. SD not visible is overlapped with the symbols.

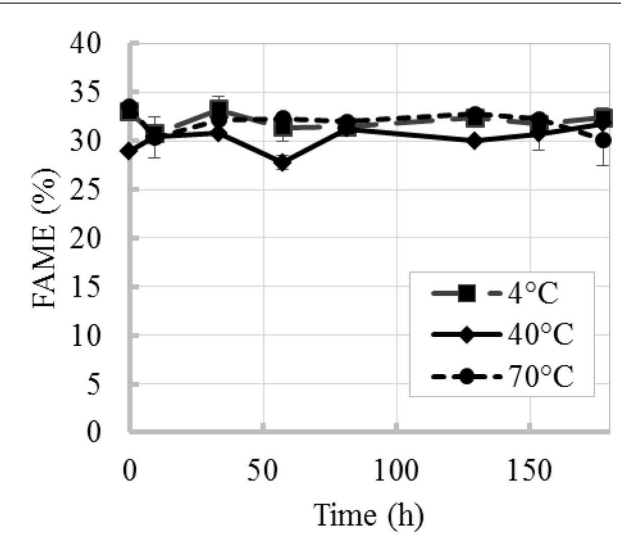

FIGURE 3 |Time evolution of percent FAME content ( $\%$ total DW) at three different temperatures (repeated experiment). Error bars represent SD from three independent experiments. SD not visible is overlapped with the symbols. 
different only between 9 and $81 \mathrm{~h}$ (ANOVA, $p<0.05$ ). In terms of the overall lipid content in the vials (mg FAME/vial), Figure 2B shows that the total lipid content in each vial as a function of time. Results show a $4.4 \%$ reduction in the $40^{\circ} \mathrm{C}$ experiment and $29.5 \%$ reduction in the $70^{\circ} \mathrm{C}$ experiment strictly based on FAME not incorporating biomass loss.

The losses per vial during the overall experiment were greater for biomass than for lipids. Biomass losses reached $43 \%$ when vials were exposed to $70^{\circ} \mathrm{C}$ while at the lowest temperature tested $\left(4^{\circ} \mathrm{C}\right)$ the impact was minimal. Losses of up to $30 \%$ in the overall lipid content per vial were observed in this study for $70^{\circ} \mathrm{C}$ experiment after $156 \mathrm{~h}$, while temperature of $40^{\circ} \mathrm{C}$ and below seemed to cause minimal impacts.

\section{DISCUSSION}

\section{OVERALL BIOMASS AND LIPID CONTENT}

The harvesting process exposes microalgae to prolonged darkness, limited gas exchange conditions, and changes in temperature, which will impact the overall composition of the cell. Under normal growth conditions microalgae perform primarily photosynthesis and minimal respiration. During photosynthesis, exogenous carbon dioxide is consumed as a carbon source, water is the electron donor, NADP is the electron acceptor, and molecular oxygen is produced as a byproduct and biomass is produced (Richmond, 2004). However, when microalgae are transferred into a containment with minimal illumination photosynthesis stops and instead respiration occurs (Montaini et al., 1995). During respiration, microalgae consume intracellular carbon reserves as carbon sources, consume molecular oxygen, and carbon dioxide and water are by-products. The respiratory metabolism of stored carbon resources and the parallel oxygen consumption ensure enough energy for temporary survival of cells. Studies have shown that Tetraselmis suecica maintained in unsealed vials at $4^{\circ} \mathrm{C}$ in darkness still had viable cells after 5 months of incubation, while hermetically sealed vessels presented limited survival (Montaini et al., 1995).

Respiration occurring during harvesting is expected to produce changes in the biochemical composition of the biomass. It has been shown in previous studies that during respiration under oxic or anoxic conditions microalgae preferentially consume energy reserves in the form of carbohydrate, followed by proteins and ultimately lipids, which were otherwise supplied by photosynthesis (Rodger Harvey et al., 1995; Aji, 2011). The consumption of internal food reserves results in mass loss (Mishra and Gamage, 2007). Such is the case of the reduction of particulate matter in Chlorella pyrenoidosa incubations under anoxic axenic conditions observed by Foree and McCarty (1970). Also, green microalgae Coelastrum sphaericum and Scenedesmus falcatus incubated under dark conditions at various temperatures $\left(16,22\right.$, and $\left.28^{\circ} \mathrm{C}\right)$ reported an overall biomass loss between 2 and $10 \%$ during the first $12 \mathrm{~h}$ of darkness (Grobbelaar and Soeder, 1985). In addition, it has been shown that respiration in Dunaliella salina exposed to $10-30^{\circ} \mathrm{C}$ produced total carbon losses in the order of $50-60 \%$ in 20 days (Degens et al., 1968).

During respiration, the energy obtained for cell maintenance is primarily derived from consumption of reserves other than lipids (Montaini et al., 1995; Rodger Harvey et al., 1995; Aji,
2011). Literature shows that total fatty acid content remained unchanged in microalgae T. suecica regardless of the time of incubation although cells were presenting loss of viability (conditions: $60 \mathrm{~g} \mathrm{~L}^{-1}$, preserved at $4^{\circ} \mathrm{C}$ in hermetically sealed vials up to 90 days) (Montaini et al., 1995). This same experiment with $T$. suecica also showed an increase in percent of total fatty acids (\% of total DW) in comparison to the value obtained for the fresh biomass at the beginning of the incubation period. Interestingly, 15 days of incubation produced a $30.4 \%$ increase, while 22 days produced $28.4 \%$ increase (Montaini et al., 1995). These results agree with the increases of percent FAME (\% of total DW) observed in this study. This percent FAME (\% of total DW) increase could be the result of (i) mass loss due to consumption of reserves (Montaini et al., 1995), and (ii) liberation of fatty acids from complex proteins and carbohydrates being consumed during respiration processes (Laurens et al., 2012).

The variability in the increases of percent FAME (\% of total DW) between the first and second experiment can also originate from variability inherent to microalgal biomass. In the repeated experiment (results in Figures 2A and 3), the biomass used in these two experiments came from different production batches resulting in the differences in initial harvested percent FAME, which impacted the trend. Several factors during microalgae cultivation affect cell composition and lipid profiles (Mayers et al., 2014; Scholz et al., 2014), e.g., different lipids convert to FAME with different efficiencies (e.g., mono-glycerides yields 83.2\% FAME, triglycerides yields 100\% FAME and phospholipids yields $64.4 \%$ FAME) (Laurens et al., 2012). Regardless of the increments in percent FAME (\% of total DW) observed in this study, the total lipid content per vial decreased with increase in temperature and was only maintained constant at low temperatures and short incubation times, thus confirming that temperature and time resulting from delays during harvesting can affect final biofuel potential.

In addition to internal reserve consumption, the perishability of biomass can also occur due to toxic effects caused by respiration/fermentation by-products accumulated in the vials (Mishra and Gamage, 2007). Literature shows in a closed container the rate of cell mortality is increased under accumulation of carbon dioxide and excretion of organic acids from fermentation (Degens et al., 1968; Montaini et al., 1995). After the respiration process consumes the available oxygen in an hermetically sealed containment (preventing gas exchange), an oxygen-limited environment will be formed (Mishra and Gamage, 2007). Under limited oxygen conditions, the rate of respiration is dramatically reduced (Grobbelaar and Soeder, 1985) and ultimately can lead to anaerobic environments. Anaerobic conditions are harsh as they lead to fermentation and decay (Mishra and Gamage, 2007). Loss of viability and increased broken cells has been observed in microalgae stored under dark anoxic conditions (Montaini et al., 1995; Heasman and Fisheries, 2001; Aji, 2011). In these systems, lower temperatures increased viability of the stored cells.

Reduction of temperature is a method for hindering mass loss and degradation, mainly because respiration and metabolic processes in live cells, as well as several post-mortem processes (e.g., catabolism, autolysis) are enzymatically driven, 
with enzyme reaction rates reduced with low temperatures (Kroemer et al., 1995; Mishra and Gamage, 2007). As found in this study, losses were generally reduced at lower temperatures. Despite low temperatures, the mechanisms producing these losses do not completely stop, hence after some time degradation will still occur.

\section{IMPLICATIONS}

Biomass and lipid losses due to unexpected delays during harvesting (e.g., equipment malfunction, uncooperative weather, and other unforeseen circumstances) or preprocessing could impact logistic and production costs. Lowering culture temperature minimizes losses but implies investments in transportation with cooled containments, thus rising equipment and operational costs. Cost of inventory will need to be considered in order to maintain reliability as a supplier, with large inventories resulting in costly stock and low inventories increasing the risk (Garstang et al., 2002). The losses observed in this study can also impact plant design parameters, such as the distance from the cultivation site to the location of the separation units as well as the number of processing units needed. In addition to economic implications, the mass losses can also affect the final net environmental impact (Chaoui and Eckhoff, 2014). The final decision about implementation of any preservation strategy will be a result of the techno-economic analysis, which needs to include the potential risks that losses during harvesting represent. Further, the experimental work presented is limited to one strain. It is expected that similar trends would be seen in other strains of microalgae.

\section{ACKNOWLEDGMENTS}

The authors would like to acknowledge the Utah State University and the Department of Energy Grant DE-EE0003114 for funding of this study, Dr. Bruce Bugbee and Dr. Curtis Adams for their support with the microalgae cultivation and Hao-Chieh Hsieh and Danna Quinn for their support.

\section{REFERENCES}

Aji, L. P. (2011). The use of algae concentrates, dried algae and algal substitutes to feed bivalves. Makara J. Sci. 15. doi:10.7454/mss.v15i1.868

Batan, L., Quinn, J., Willson, B., and Bradley, T. (2010). Net energy and greenhouse gas emission evaluation of biodiesel derived from microalgae. Environ. Sci. Technol. 44, 7975-7980. doi:10.1021/es102052y

Beal, C., Hebner, R., Webber, M., Ruoff, R., and Seibert, A. F. (2012). The energy return on investment for algal biocrude: results for a research production facility. Bioenerg. Res. 5, 341-362. doi:10.1007/s12155-011-9128-4

Chaoui, H., and Eckhoff, S. (2014). "Biomass feedstock storage for quantity and quality preservation," in Engineering and Science of Biomass Feedstock Production and Provision, eds Y. Shastri, A. Hansen, L. Rodríguez, and K. C. Ting (New York, NY: Springer), 165-193.

Davis, R., Aden, A., and Pienkos, P. T. (2011). Techno-economic analysis of autotrophic microalgae for fuel production. Appl. Energy 88, 3524-3531. doi:10.1016/j.apenergy.2011.04.018

Davis, R. E., Fishman, D. B., Frank, E. D., Johnson, M. C., Jones, S. B., Kinchin, C. M., et al. (2014). Integrated evaluation of cost, emissions, and resource potential for algal biofuels at the national scale. Environ. Sci. Technol. 48, 6035-6042. doi:10.1021/es4055719

Degens, E. T., Guillard, R. R. L., Sackett, W. M., and Hellebust, J. A. (1968). Metabolic fractionation of carbon isotopes in marine plankton - I. Temperature and respiration experiments. Deep Sea Res. Oceanogr. Abstr. 15, 1-9. doi:10.1016/0011-7471(68)90024-7
Foree, E. G., and McCarty, P. L. (1970). Anaerobic decomposition of algae. Environ. Sci. Technol. 4, 842-849. doi:10.1021/es60045a005

Garstang, J., Weekes, A., Poulter, R., and Bartlett, D. (2002). Identification and Characterization of Factors Affecting Losses in the Large-Scale, Non-Ventilated Bulk Storage of Wood Chips and Development of Best Storage Practices. Gloucestershire: Report to the UK Department of Trade and Industry.

Grobbelaar, J. U., and Soeder, C. J. (1985). Respiration losses in planktonic green algae cultivated in raceway ponds. J. Plankton Res. 7, 497-506. doi:10.1093/ plankt/7.4.497

Heasman, M. P., and Fisheries, N. (2001). Production of Micro-algal Concentrates for Aquaculture: Development and Evaluation of Harvesting, Preservation, Storage and Feeding Technology. Nelson Bay: NSW Fisheries.

Jones, S., Davis, R., Zhu, Y., Kinchin, C., Anderson, D., Hallen, R., et al. (2014). Process Design and Economics for the Conversion of Algal Biomass to Hydrocarbons: Whole Algae Hydrothermal Liquefaction and Upgrading. Richland, WA: U.S. Department of Energy Bioenergy Technologies Office.

Khan, S. A., Rashmi, Hussain, M. Z., Prasad, S., and Banerjee, U. C. (2009). Prospects of biodiesel production from microalgae in India. Renew. Sustain. Energ. Rev. 13, 2361-2372. doi:10.1016/j.rser.2009.04.005

Kroemer, G., Petit, P., Zamzami, N., Vayssière, J. L., and Mignotte, B. (1995). The biochemistry of programmed cell death. FASEB J. 9, 1277-1287.

Laurens, L. L., Quinn, M., Van Wychen, S., Templeton, D., and Wolfrum, E. (2012). Accurate and reliable quantification of total microalgal fuel potential as fatty acid methyl esters by in situ transesterification. Anal. Bioanal. Chem. 403, 167-178. doi:10.1007/s00216-012-5814-0

Lundquist, T. J., Woertz, I. C., Quinn, N. W. T., and Benemann, J. R. (2010). A Realistic Technology and Engineering Assessment of Algae Biofuel Production. Berkeley, CA: Energy Biosciences Institute.

Mata, T. M., Martins, A. A., and Caetano, N. S. (2010). Microalgae for biodiesel production and other applications: a review. Renew. Sustain. Energ. Rev. 14, 217-232. doi:10.1016/j.rser.2009.07.020

Mayers, J. J., Flynn, K. J., and Shields, R. J. (2014). Influence of the N:P supply ratio on biomass productivity and time-resolved changes in elemental and bulk biochemical composition of Nannochloropsis sp. Bioresour. Technol. 169, 588-595. doi:10.1016/j.biortech.2014.07.048

Mishra, V. K., and Gamage, T. V. (2007). "Postharvest physiology of fruit and vegetables," in Handbook of Food Preservation, Second Edn, ed. M. S. Rahman (London: CRC press).

Montaini, E., Chini Zittelli, G., Tredici, M. R., Molina Grima, E., Fernández Sevilla, J. M., and Sánchez Pérez, J. A. (1995). Long-term preservation of Tetraselmis suecica: influence of storage on viability and fatty acid profile. Aquaculture 134, 81-90. doi:10.1016/0044-8486(95)00034-Y

Quinn, J. C., Smith, T. G., Downes, C. M., and Quinn, C. (2014). Microalgae to biofuels lifecycle assessment-multiple pathway evaluation. Algal Res. 4, 116-122. doi:10.1186/1754-6834-6-88

Quinn, J. C., Yates, T., Douglas, N., Weyer, K., Butler, J., Bradley, T. H., et al. (2012). Nannochloropsis production metrics in a scalable outdoor photobioreactor for commercial applications. Bioresour. Technol. 117, 164-171. doi:10.1016/j. biortech.2012.04.073

Richmond, A. (2004). Handbook of Microalgal Culture Biotechnology and Applied Phycology. Oxford; Ames, IA: Blackwell Science. Available at: http://site.ebrary. com/id/10249036

Rodger Harvey, H., Tuttle, J. H., and Tyler Bell, J. (1995). Kinetics of phytoplankton decay during simulated sedimentation: changes in biochemical composition and microbial activity under oxic and anoxic conditions. Geochim. Cosmochim. Acta 59, 3367-3377. doi:10.1016/0016-7037(95)00217-N

Rogers, J. N., Rosenberg, J. N., Guzman, B. J., Oh, V. H., Mimbela, L. E., Ghassemi, A., et al. (2014). A critical analysis of paddlewheel-driven raceway ponds for algal biofuel production at commercial scales. Algal Res. 4, 76-88. doi:10.1016/j.algal.2013.11.007

Scholz, M. J., Weiss, T. L., Jing, J., Roth, R., Goodenough, U., Posewitz, M. C., et al. (2014). "Ultrastructure and composition of the Nannochloropsis gaditana cell wall," in 4th International Conference on Algal Biomass, Biofuels and Bioproducts.

Sills, D. L., Paramita, V., Franke, M. J., Johnson, M. C., Akabas, T. M., Greene, C. H., et al. (2012). Quantitative uncertainty analysis of life cycle assessment for algal biofuel production. Environ. Sci. Technol. 47, 687-694. doi:10.1021/ es3029236 
Thilakaratne, R., Wright, M. M., and Brown, R. C. (2014). A techno-economic analysis of microalgae remnant catalytic pyrolysis and upgrading to fuels. Fuel 128, 104-112. doi:10.1016/j.fuel.2014.02.077

Woertz, I. C., Benemann, J. R., Du, N., Unnasch, S., Mendola, D., Mitchell, B. G., et al. (2014). Life cycle GHG emissions from microalgal biodiesel - a CA-GREET model. Environ. Sci. Technol. 48, 6060-6068. doi:10.1021/es403768q

Wychen, S. V., and Laurens, L. M. L. (2013). Determination of Total Lipids as Fatty Acid Methyl Esters (FAME) by In situ Transesterification. Golden, CO: National Renewable Energy Laboratory.

Conflict of Interest Statement: The authors declare that the research was conducted in the absence of any commercial or financial relationships that could be construed as a potential conflict of interest.
Received: 01 September 2014; accepted: 21 March 2015; published online: 15 April 2015.

Citation: Napan K, Christianson T, Voie K and Quinn JC (2015) Quantitative assessment of microalgae biomass and lipid stability post-cultivation. Front. Energy Res. 3:15. doi: 10.3389/fenrg.2015.00015

This article was submitted to Bioenergy and Biofuels, a section of the journal Frontiers in Energy Research.

Copyright (C) 2015 Napan, Christianson, Voie and Quinn. This is an open-access article distributed under the terms of the Creative Commons Attribution License (CC BY). The use, distribution or reproduction in other forums is permitted, provided the original author(s) or licensor are credited and that the original publication in this journal is cited, in accordance with accepted academic practice. No use, distribution or reproduction is permitted which does not comply with these terms. 